Selcan Sinaci*, Doga Fatma Ocal, Eda Ozden Tokalioglu, Filiz Halici Ozturk, Selvi Aydin Senel, Levent Huseyin Keskin, Ozlem Moraloglu Tekin and Dilek Sahin

\title{
Cardiotocographic features in COVID-19 infected pregnant women
}

https://doi.org/10.1515/jpm-2021-0132

Received March 22, 2021; accepted July 22, 2021; published online August 19, 2021

\section{Abstract}

Objectives: We aimed to evaluate the cardiotocograph (CTG) traces of 224 women infected with novel coronavirus 2019 (COVID-19) and analyze whether changes in the CTG traces are related to the severity of COVID-19.

Methods: We designed a prospective cohort study. Twohundred and twenty-four women who had a single pregnancy of 32 weeks or more, and tested positive for SARS-CoV-2 were included. Clinical diagnosis and classifications were made according to the Chinese management guideline for COVID-19 (version 6.0). Patients were classified into categories as mild, moderate, severe and the CTG traces were observed comparing the hospital admission with the third day of positivity.

Results: There was no statistically significant relationship between COVID-19 severity and CTG category, variability, tachycardia, bradycardia, acceleration, deceleration, and uterine contractility, Apgar 1st and 5th min.

Conclusions: Maternal COVID-19 infection can cause changes that can be observed in CTG. Regardless of the severity of the disease, COVID-19 infection is associated with changes in CTG. The increase in the baseline is the most obvious change.

Keywords: baseline fetal heart ratio (FHR); cardiotocography (CTG); COVID-19; cytokine storm; deceleration.

*Corresponding author: Selcan Sinaci, Department of Obstetrics and Gynecology, Ministry of Health, Ankara City Hospital, 1604th Street, No. 9, Cankaya, Ankara 06800, Turkey,

E-mail: selcansinaci@gmail.com. https://orcid.org/0000-0003-31184036

Doga Fatma Ocal, Eda Ozden Tokalioglu, Filiz Halici Ozturk and Selvi Aydin Senel, Department of Obstetrics and Gynecology, Ministry of Health, Ankara City Hospital, Ankara, Turkey. https://orcid.org/00000003-4901-0544 (E. Ozden Tokalioglu)

Levent Huseyin Keskin, Ozlem Moraloglu Tekin and Dilek Sahin, Department of Obstetrics and Gynecology, Ministry of Health, Ankara City Hospital, Ankara, Turkey; and University of Health Sciences, Ankara City Hospital, Ankara, Turkey

\section{Introduction}

Novel coronavirus 2019 (COVID-19) is an emerging public health problem caused by severe acute respiratory syndrome coronavirus 2 (SARS-CoV-2). Since its first identification in Wuhan in December 2019, it has been increasing rapidly at an accelerating rate with over 100 million individuals infected [1]. Previous coronavirus epidemics; the severe acute respiratory syndrome coronavirus (SARS-CoV) and the Middle East respiratory syndrome coronavirus (MERS-CoV), have shown that pregnant women and their fetuses are particularly susceptible to poor outcomes such as maternal mortality and morbidity, and perinatal death [2]. There is currently not sufficient knowledge about pregnant women and their complications with COVID-19 in the literature.

Similar to nonpregnant women, fever, cough, myalgia are the most common symptoms of COVID-19 in pregnant women [3, 4]. Although the limited data we have suggests lack of evidence for higher maternal or fetal risks and vertical transmission, fetal complications including preterm labor, fetal growth restriction, fetal distress, and fetal demise have been reported $[3,5,6]$.

Cardiotocograph (CTG) is used to record the fetal heart rate (FHR) and determine fetal well-being in order to detect the signs of intrapartum hypoxia [7]. CTG has four features to analyze; baseline FHR, variability, accelerations, and decelerations. These parameters show the activity of fetal somatic and autonomic nervous systems and the oxygenation of the fetal myocardium and brain. In the presence of utero-placental insufficiency, due to hypoxia the fetus switches its metabolism from aerobic to anaerobic and reduces the myocardial workload, and this is reflected in the CTG trace as deceleration [8]. Maternal inflammatory conditions as well as maternal pyrexia can affect fetus and result as baseline tachycardia and decelerations in the CTG trace [9].

In recent studies, it has been shown that SARS-CoV-2 causes an excessively increased response in proinflammatory cytokines (e.g., interleukin-6 [IL-6], interleukin-1 $\beta$ [IL-1 $\beta]$, tumor necrosis factor- $\alpha$ [TNF- $\alpha]$ ) and chemokines (e.g., monocyte chemoattractant protein-1 [MCP-1/CCL2]), and hyperactivation of immune cells, 
causing infiltration of inflammatory cells in the lungs and hypercytokinemia with an exaggerated maternal innate immune response. This condition, called "cytokine storm" is associated with the severity of COVID-19 [10-13]. Not virus replication itself but cytokine storm leads to acute respiratory distress syndrome and multiorgan failure $[10,11]$. Triad of maternal hypoxia seconder to the ARDS, cytokine storm, and hypercoagulability is associated with the risk of placental intervillous thrombosis and infarction $[14,15]$.

Despite the lack of evidence about COVID-19 vertical transmission to fetus [16], it is likely that fetus would have a reactive response secondary to maternal inflammatory changes and pyrexia, resulting FHR changes reflected in the CTG trace. Maternal inflammatory and hypercoagulable state might be seen as decelerations, absence of variability, and bradycardia on the CTG secondary to uteroplacental insufficiency and placental or umbilical venous thrombosis. Maternal fever as well as maternal inflammatory state, can reduce the utero-placental oxygen transfer and lead to irritation of uterine myometrium which results with increased contractility [17]. In rare cases, severe maternal hypoxia can result as a sinusoidal pattern on the CTG [18].

Since we think that COVID-19 affects FHR as in inflammatory states, in this study, for the first time we aimed to evaluate the CTG traces of 224 pregnant women infected with COVID-19 and analyze whether changes in the CTG traces are related to severity of COVID-19.

\section{Materials and methods}

\section{Procedure and patient selection}

This prospective cohort study was carried out between August and October 2020 at Ministry of Health Ankara City Hospital, the main public maternity hospital which handles above 15,000 deliveries yearly and covers all surgical and medical disciplines.

A total of 224 women who had a single pregnancy of 32 weeks or more, and tested positive for SARS-CoV-2 by use of quantitative RT-PCR (qRT-PCR) on samples from the respiratory tract were included in the study. The patients were recruited from the COVID-19 inpatient wards of the department of obstetrics and gynecology.

CTG traces were observed comparing the hospital admission with the third day of positivity. We chose day 3 to repeat the CTG because SARS-CoV-2 viral replication is maximal on day 3 [19]. Clinical diagnosis and classifications were made according to the Chinese management guideline for COVID-19 (version 6.0) [20]. Patients were classified into categories as mild, moderate, severe.

Patients were also divided into two groups whether they received treatment for COVID-19 or not. COVID-19 treatment was formulated according to the therapy plan applied in our clinic for pregnant patients. As outlined by Sahin et al. [3], with COVID-19 therapy, patients received several combinations of the following medications: lowmolecular weight heparin, hydroxychloroquine, lopinavir-ritonavir, systemic corticosteroid, favipiravir, $N$-acetylcysteine, high-dose vitamin C, HuIL-1Ra, and convalescent plasma in addition to nasal oxygen therapy, high-flow nasal cannula, and invasive mechanical ventilation.

Those who have maternal systemic diseases (diabetes, cardiovascular diseases, hypertensive diseases of pregnancy, asthma, thromboembolic disorders, inflammatory bowel diseases, autoimmune connective tissue diseases, other infectious diseases), multifetal pregnancy, and fetal chromosomal and structural anomaly were excluded from the study.

\section{Cardiotocography procedure (CTG)}

The FHR and the mother's uterine contractions were detected electronically on a paper strip known as a CTG. This was done by placing two Doppler ultrasound transducers on the mother's abdomen, one at the level of the fetal heart to monitor the FHR and one at fundus to detect the activity of the uterine muscles. A conductive gel should be placed between the FHR sensor and the abdomen to ensure adequate transmission of sound waves. This method can be done continuously (usually in labor) or intermittently [21]. We used external cardiotocography for intermittent monitoring. We observed all the CTG traces when mothers were at semi-sitting position, $1 \mathrm{~h}$ after breakfast in the morning.

Features and normal parameters of the CTG specified in Table 1 according to the 2008 NICE guideline on EFM definitions [22]. In our study, we interpreted CTG features such as FHR, baseline FHR, variability, acceleration, deceleration, and evaluated the CTG traces of the patients and compared initial CTG traces with the third day. Since the visual analysis of CTG may significantly suffer from intra and interobserver variation, three different and highly experienced doctors among the authors separately evaluated each CTG trace. The physicians were blinded to the patients' COVID-19 severity category and to the results of each others' reviews. Moreover, we divided the patients into categories according to the severity of the COVID disease.

\section{Three-tier fetal heart rate}

In our study, we categorized the FHR tracings according to the threetier FHR system [22] and divided the patients into groups. The threetier FHR system was designed for women in labor, hence contains intrapartum criteria. However, in our study, we mostly interpreted antepartum tracings with this system. $22.8 \%$ (51/224) of the patients were in labor. While the standard antepartum classification system provides the opportunity to be interpreted as reactive vs. non-reactive, the three-tier system analysis was more appropriate for our purpose as it includes detailed components we desired to evaluate.

Category I FHR tracings: Normal, strongly predictive of normal fetal acid-base status and routine care is enough, no specific action is required. These tracings include all of the following:

- Baseline FHR: 110-160 beats/min

- Baseline FHR variability: moderate

- Late or variable decelerations: absent

- Early decelerations: present or absent

- Accelerations: present or absent 
Table 1: Electronic fetal monitoring (EFM) definitions.

\begin{tabular}{|c|c|}
\hline CTG feature & Normal parameters \\
\hline Baseline FHR & $\begin{array}{l}\text { - Baseline is determined during a } 10 \text { min segment, excluding accelerations and decelerations, and periods of } \\
\text { marked variability (>25 bpm) and is described in } 5 \mathrm{bpm} \text { increments (e.g., a baseline can be } 130 \text { or } 135 \mathrm{bpm} \text {, but is } \\
\text { not described as } 132 \text { or } 133 \mathrm{bpm}) \text {. } \\
\text { - } \text { Baseline must be minimum } 2 \text { min in any } 10 \text { min segment } \\
\text { - Normal FHR baseline: } 110-160 \mathrm{bpm} \\
\text { - Tachycardia: FHR baseline is greater than } 160 \mathrm{bpm} \\
\text { - Bradycardia: FHR baseline is less than } 110 \mathrm{bpm}\end{array}$ \\
\hline Baseline variability & 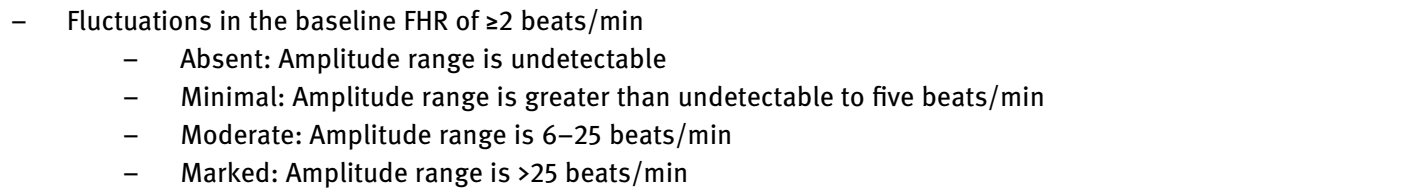 \\
\hline Acceleration & $\begin{array}{l}\text { - Visually apparent abrupt increase (onset to peak in less than } 30 \mathrm{~s} \text { ) in the FHR } \\
\text { - } \quad \geq 32 \text { gestational week } 15 \mathrm{bpm} \text { rise in the FHR from the normal baseline lasting for } \geq 15 \mathrm{~s}-<2 \mathrm{~min} \\
\text { - } \quad<32 \text { gestational week } 10 \mathrm{bpm} \text { rise in the FHR from the normal baseline lasting for } \geq 10 \mathrm{~s}-<2 \mathrm{~min} \\
\text { - Prolonged acceleration; } 2-10 \mathrm{~min} \\
\text { - If an acceleration lasts }>10 \mathrm{~min} \text {, it is a baseline change }\end{array}$ \\
\hline Early deceleration & $\begin{array}{l}\text { - Visually apparent usually symmetrical gradual decrease associated with a uterine contraction } \\
\text { - The nadir of the deceleration occurs at the same time as the peak of the contraction. } \\
\text { - In most cases the onset, nadir, and recovery of the deceleration are coincident with the beginning, peak, and } \\
\text { ending of the contraction, respectively or are of a shorter duration than the contraction. }\end{array}$ \\
\hline Late deceleration & $\begin{array}{l}\text { - Visually apparent usually symmetrical gradual decrease and return of the FHR associated with a uterine } \\
\text { contraction } \\
\text { - The deceleration is delayed in timing, with the nadir of the deceleration occurring after the peak of the contraction. } \\
\text { - In most cases, the onset, nadir, and recovery of the deceleration occur after the beginning, peak, and ending of the } \\
\text { contraction, respectively. }\end{array}$ \\
\hline Variable deceleration & $\begin{array}{l}\text { - Visually apparent abrupt decrease in FHR } \\
\text { - } \quad \text { From the onset of the deceleration to the beginning of the FHR nadir of }<30 \mathrm{~s} \\
\text { - } \quad \text { The decrease in FHR is calculated from the onset to the nadir of the deceleration. } \\
\text { - } \quad \text { The decrease in FHR is } 15 \text { beats/min or greater, lasting } 15 \mathrm{~s} \text { or greater, and less than } 2 \text { min in duration. } \\
\text { - } \quad \text { When variable decelerations are associated with uterine contractions, their onset, depth, and duration commonly } \\
\quad \text { vary with successive uterine contractions. }\end{array}$ \\
\hline $\begin{array}{l}\text { Prolonged } \\
\text { deceleration }\end{array}$ & $\begin{array}{l}\text { - Visually apparent decrease in the FHR below the baseline } \\
\text { - } \quad \geq 15 \mathrm{bpm} \text { decrease in the FHR lasting for } \geq 2-<10 \mathrm{~min} \\
\text { - } \quad \text { If a deceleration lasts } 10 \mathrm{~min} \text { or longer, it is a baseline change }\end{array}$ \\
\hline $\begin{array}{l}\text { Recurrent } \\
\text { deceleration }\end{array}$ & - Deceleration occurs $\geq 50 \%$ of uterine contractions in any $20 \mathrm{~min}$ \\
\hline $\begin{array}{l}\text { Intermittent } \\
\text { deceleration }\end{array}$ & - Deceleration occurs $<50 \%$ of uterine contractions in any $20 \mathrm{~min}$ \\
\hline Sinusoidal pattern & $\begin{array}{l}\text { - Visually apparent, smooth, sine wave-like undulating pattern in FHR baseline with a cycle frequency of } 3-5 \text { per } \\
\text { minute which persists for } \geq 20 \mathrm{~min}\end{array}$ \\
\hline Uterine contractions & $\begin{array}{l}\text { - } \quad \text { Normal: } \leq 5 \text { contractions in } 10 \mathrm{~min} \\
\text { - Tachysystole: }>5 \text { contractions in } 10 \mathrm{~min}\end{array}$ \\
\hline
\end{tabular}

FHR, fetal heart rate; bpm: beats/min.

Category II FHR tracings: Indeterminate, are not predictive of abnormal fetal acid-base status, require evaluation and continued surveillance and re-evaluation. These tracings include all tracings not categorized as Category I or category III, any of the following:

- Bradycardia not accompanied by absent variability

- Tachycardia

- Minimal or marked baseline FHR variability

- Absent variability without recurrent decelerations

- Absence of induced accelerations after fetal stimulation
- Recurrent variable decelerations with minimal or moderate variability

- Prolonged decelerations

- Recurrent late decelerations with moderate variability

- Variable decelerations with other characteristics, such as slow return to baseline FHR

Category III FHR tracings: Abnormal, predictive of abnormal fetal acid-base status and require prompt intervention. These tracings include either: 
- Absent variability with any of the following:

- Recurrent late decelerations

- Recurrent variable decelerations

- Bradycardia

- Sinusoidal pattern

\section{Statistical analyses}

SPSS for Microsoft Windows 24.0 (SPSS Inc., Armonk, NY, USA) used for statistical analyses. Frequency tables and descriptive statistics were used in the interpretation of the findings.

In this study, the relationship between two qualitative variables, the expected value levels were analyzed by the Fisher-Exact and Pearson- $\chi^{2}$ test. The "Mann-Whitney U" test (Z-table value) was used to compare the measurement values of two independent groups, and the "Wilcoxon" test (Z-table value) method was used to compare the measurement values of the two dependent groups. $p<0.05$ indicates a significant correlation and $p>0.05$ means there is no significant correlation during the analysis. Backward LR model was used as the binary logistic regression method to determine the factors affecting the severity of COVID-19 disease.

\section{Results}

\section{Participant characteristics}

The distribution of the patients regarding to age (year), gravidity, parity, abortion, and gestational week were given in Table 2.

It was determined that $84.3 \%(189 / 224)$ were in the mild category in terms of COVID-19 severity, $96.4 \%$ (216/224) had no change in the COVID-19 category, 83.9\% (188/224) did not receive medical treatment for COVID-19. It was determined that $72.7 \%$ (163/224) of the patients' CTG category was one and the CTG category did not change in 82.1\% (184/224) patients. Eight newborns had APGAR scores $<7$ at 5 th $\mathrm{min}$ and required neonatal intensive care unit admission. All eight newborns were tested negative for SARS-CoV-2 RT-PCR. While five of the mothers of those newborns had mild COVID-19 disease, three of them had severe-critic COVID-19. All eight mothers whose newborns admitted to the NICU were delivered by cesarean. In four cases, cesarean indication was fetal distress and the CTG traces were in category 2 or 3.

\section{CTG characteristics}

The distribution of Apgar 1st min, Apgar 5th min, birth weight and lowest oxygen saturation were given in the Table 3. It was observed that $25.0 \%$ (56/224) of patients had minimal or absence of variability (Figure 1), while 4.0\%
Table 2: Obstetric characteristics of the sample.

\begin{tabular}{|c|c|c|c|}
\hline Variable $(n=224)$ & Median, min-max & $\mathbf{n}$ & $\%$ \\
\hline Maternal age, years & $28.0[16.0-46.0]$ & & \\
\hline Gravidity & $2.0[0.0-6.0]$ & & \\
\hline Parity & $1.0[0.0-6.0]$ & & \\
\hline Previous miscarriage & $0.0[0.0-5.0]$ & & \\
\hline \multicolumn{4}{|c|}{ Previous route of delivery } \\
\hline Vaginal & & 77 & 34.3 \\
\hline Cesarean & & 52 & 23.2 \\
\hline None & & 95 & 42.4 \\
\hline Gestational week & $37.0[32.0-41.0]$ & & \\
\hline \multicolumn{4}{|l|}{ COVID-19 categories } \\
\hline Mild & & 189 & 84.3 \\
\hline Moderate & & 21 & 9.3 \\
\hline Severe & & 14 & 6.2 \\
\hline \multicolumn{4}{|c|}{ COVID-19 category change } \\
\hline No & & 217 & 96.9 \\
\hline Mild to moderate & & 2 & 0.9 \\
\hline Moderate to severe & & 2 & 0.9 \\
\hline Severe to moderate & & 3 & 1.3 \\
\hline \multicolumn{4}{|l|}{ COVID-19 treatment } \\
\hline No & & 188 & 83.9 \\
\hline Yes & & 36 & 16.0 \\
\hline \multicolumn{4}{|l|}{ CTG categories } \\
\hline Category 1 & & 163 & 72.7 \\
\hline Category 2 & & 50 & 22.4 \\
\hline Category 3 & & 11 & 4.9 \\
\hline \multicolumn{4}{|l|}{ CTG category change } \\
\hline No difference & & 184 & 82.1 \\
\hline Category 1-2 & & 12 & 5.4 \\
\hline Category 2-3 & & 3 & 1.3 \\
\hline Category 1-3 & & 8 & 3.6 \\
\hline Category 2-1 & & 13 & 5.8 \\
\hline Category 3-1 & & 4 & 1.8 \\
\hline
\end{tabular}

(9/224) had ZigZag pattern (exaggerated variability) [23] (Figure 2). A total of $13.4 \%$ (30/224) had no acceleration (Figure 3), and $25.0 \%$ (56/224) showed types of decelerations (Figures 3 and 4) A total of 5.4\% (12/224) of the patients had tachycardia (Figure 5), while 1.3\% (3/224) had bradycardia. $66.5 \%(149 / 224)$ of the patients had uterine contractility, 44.6\% (100/224) patients gave birth with C/S, and $90.9 \%$ (140/224) did not receive induction. About 22.8\% (51/224) of the patients were in labor and 31.2\% (70/224) of the patients did not give birth during our study period.

There was a statistically significant difference in terms of baseline FHR values between first and last CTG traces $(\mathrm{p}<0.05)$. Final baseline FHR values were significantly higher than the initial baseline FHR value.

There was no statistically significant relationship between COVID-19 severity and CTG category, CTG category change, variability, tachycardia, bradycardia, acceleration, deceleration, and uterine contractility $(\mathrm{p}>0.05)$ (Table 4). 
Table 3: CTG characteristics of the sample.

\begin{tabular}{|c|c|c|c|c|}
\hline Variable $(n=224)$ & Mean $\pm \mathbf{S D}^{\mathbf{a}}$ & Median [min-max] & $\mathbf{n}$ & $\%$ \\
\hline \multicolumn{5}{|l|}{ Variability } \\
\hline Absence of variability & & & 8 & 3.6 \\
\hline Minimal variability & & & 48 & 21.4 \\
\hline Normal variability & & & 159 & 70.9 \\
\hline Marked variability ${ }^{\mathrm{b}}$ & & & 9 & 4.0 \\
\hline \multicolumn{5}{|l|}{ Tachycardia/bradycardia } \\
\hline No & & & 209 & 93.3 \\
\hline Tachycardia & & & 12 & 5.4 \\
\hline Bradycardia & & & 3 & 1.3 \\
\hline \multicolumn{5}{|l|}{ Acceleration } \\
\hline No & & & 30 & 13.4 \\
\hline Yes & & & 194 & 86.6 \\
\hline \multicolumn{5}{|l|}{ Deceleration } \\
\hline No & & & 168 & 75.0 \\
\hline Early & & & 5 & 2.2 \\
\hline Variable & & & 29 & 12.9 \\
\hline Late & & & 19 & 8.5 \\
\hline Prolonged & & & 3 & 1.4 \\
\hline \multicolumn{5}{|l|}{ Uterine contractility } \\
\hline No & & & 62 & 27.7 \\
\hline Yes & & & 149 & 66.5 \\
\hline Tachysystole & & & 9 & 4.0 \\
\hline Saw-tooth ${ }^{c}$ & & & 4 & 1.8 \\
\hline \multicolumn{5}{|l|}{ Route of delivery } \\
\hline Vaginal delivery & & & 54 & 24.1 \\
\hline Cesarean delivery & & & 100 & 44.6 \\
\hline Ongoing pregnancy & & & 70 & 31.2 \\
\hline \multicolumn{5}{|l|}{ Birth induction } \\
\hline Yes & & & 14 & 9.1 \\
\hline No & & & 140 & 90.9 \\
\hline \multicolumn{5}{|l|}{ Cesarean indications } \\
\hline Previous cesarean delivery & & & 35 & 35 \\
\hline Preterm labor & & & 11 & 11 \\
\hline Fetal distress & & & 31 & 31 \\
\hline Cephalopelvic disproportion & & & 8 & 8 \\
\hline Induction failure & & & 7 & 7 \\
\hline Macrosomia & & & 1 & 1 \\
\hline Malpresentation & & & 3 & 3 \\
\hline Maternal health condition & & & 4 & 4 \\
\hline Apgar 1st min & $7.52 \pm 0.97$ & $8.0[1.0-9.0]$ & & \\
\hline Apgar 5th min & $9.07 \pm 0.83$ & $9.0[6.0-10.0]$ & & \\
\hline Birth weight, $\mathrm{g}$ & $3,087.79 \pm 608.24$ & $3,180.0[879.0-4,130.0]$ & & \\
\hline Minimum $\mathrm{O}_{2}$ saturation & $96.23 \pm 1.99$ & $96.0[88.0-99.0]$ & & \\
\hline
\end{tabular}

${ }^{a}$ Standard deviation. ${ }^{b}$ Increased variability which amplitude range is $>25$ beats/min for 1 min or longer was defined as ZigZag pattern in the literature [23]. 'Shark-teeth-like increased uterine contractions.

There was no statistically significant difference in terms of gestational week, first and last baseline FHR values, birth weight, Apgar 1st and 5th min between COVID-19 categories ( $p>0.05)$. A statistically significant difference was found in terms of the lowest oxygen saturation value according to COVID-19 categories $(\mathrm{p}<0.05)$. The lowest oxygen saturation values of the moderate and severe COVID-19 patients were statistically significantly lower than the mild ones (Table 5).

As a result of the backward logistic regression analysis, utilizing all available parameters and the COVID-19 severity, the optimal model was created and presented in Table 6.

It was observed that the COVID-19 categories affected the final baseline FHR value. The baseline value increases 


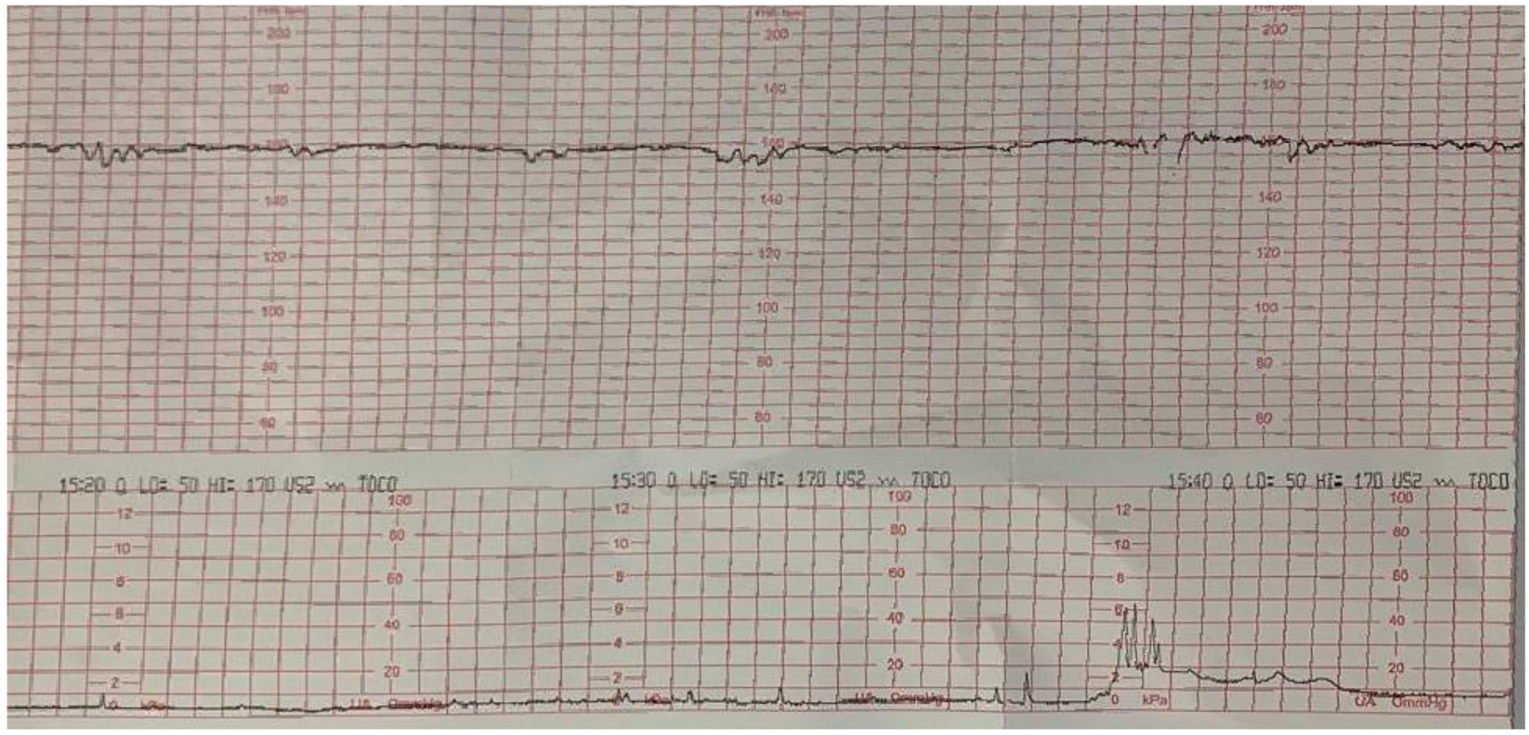

Figure 1: Minimal variability in the CTG trace of a patient with COVID-19 infection.

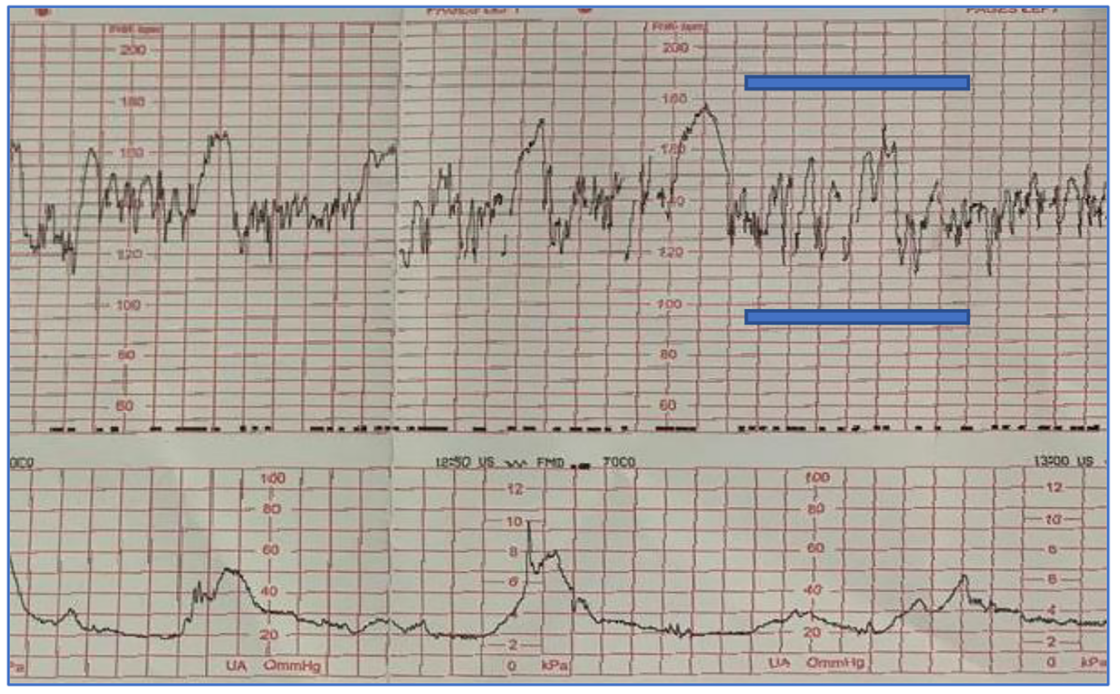

Figure 2: Marked variability in the CTG trace of a patient with COVID-19 infection.

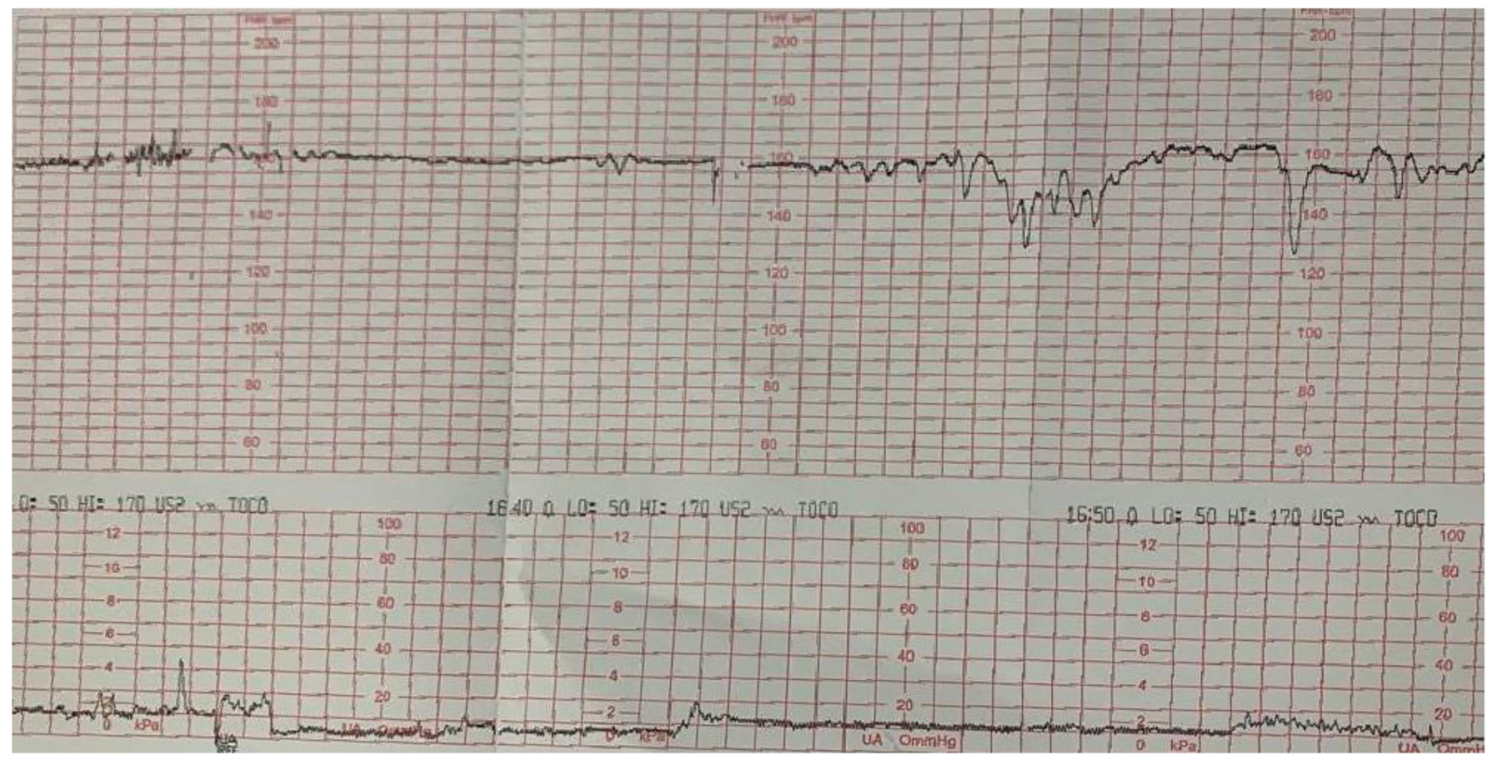

Figure 3: Loss of accelerations with variable decelerations in the CTG trace of a patient with COVID-19 infection. 


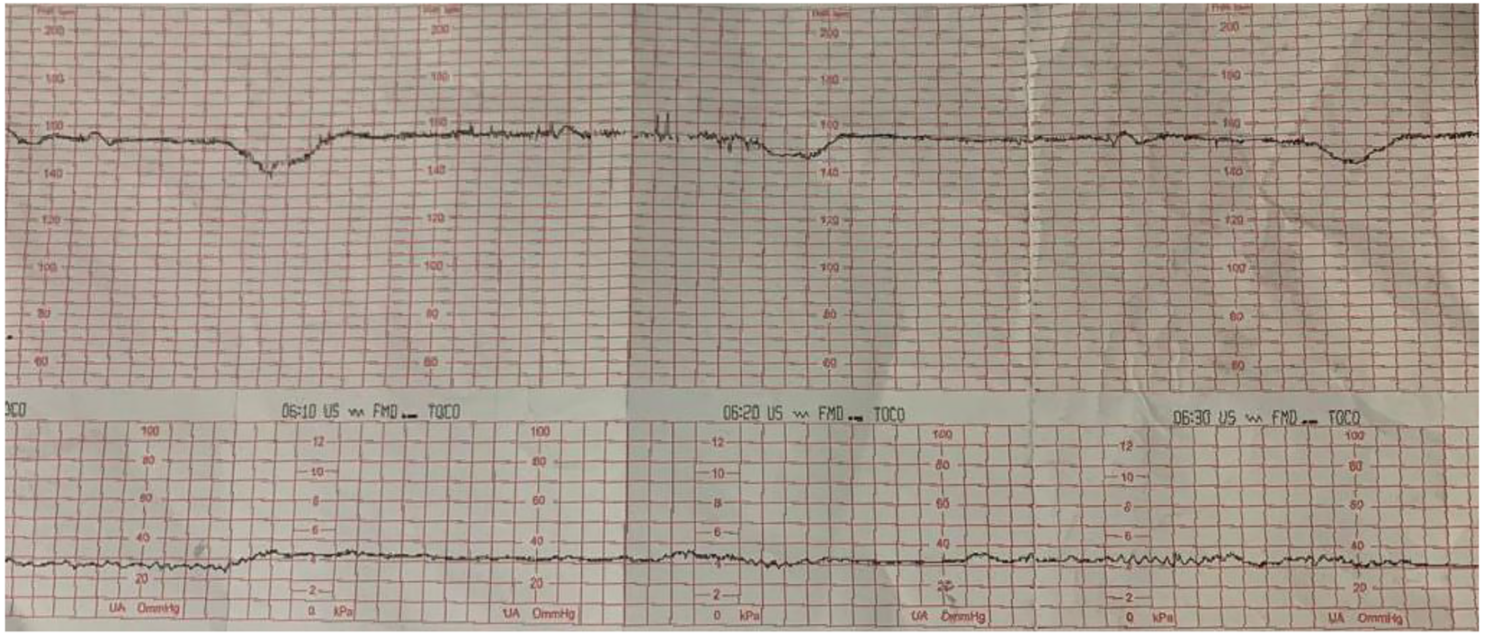

Figure 4: Recurrent decelerations with minimal variability in the CTG trace of a patient with COVID-19 infection.

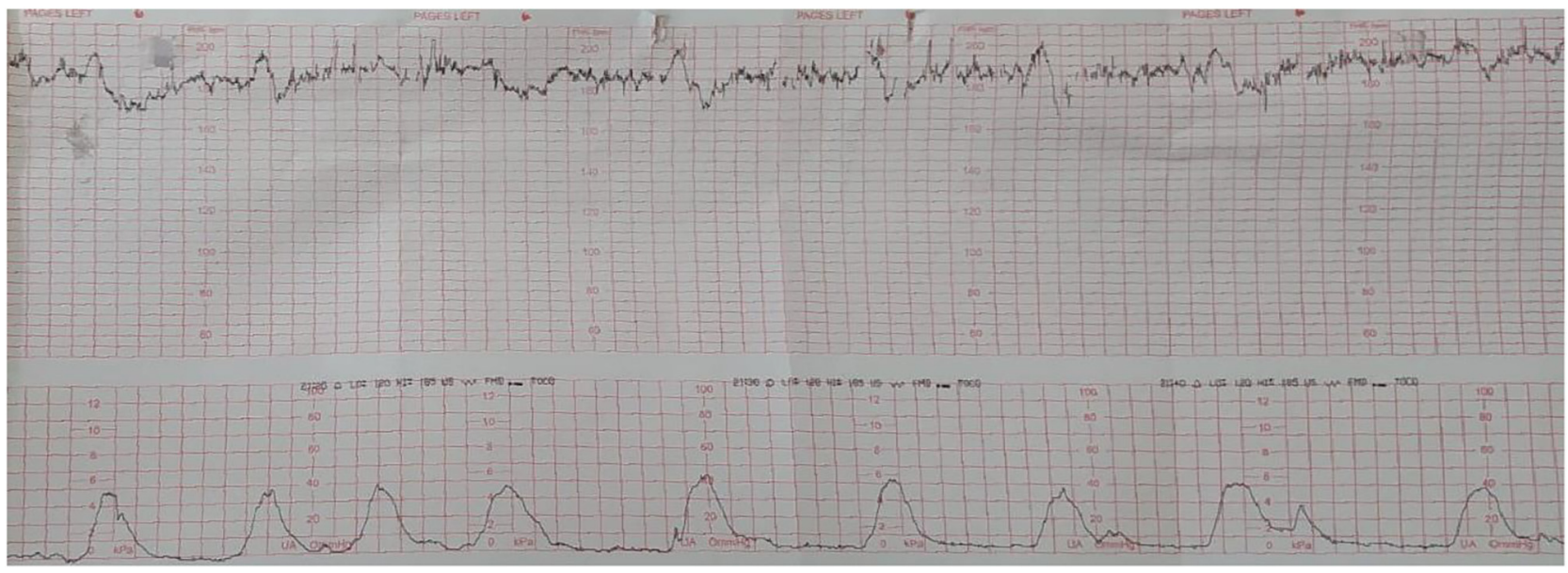

Figure 5: Fetal tachycardia in the CTG trace of a patient with COVID-19 infection.

by one beats/min (bpm), when the risk of being COVID-19 moderate or severe increases by $5.3 \%(\mathrm{OR}=1.053)$.

\section{Discussion}

To the best of our knowledge, this is the first study with a significantly high number of patients which analyzed the CTG changes in maternal COVID-19 infection using threetier FHR system [22] and documented all CTG trace parameters according to the COVID-19 severity.

Numerous factors or circumstances have influence on the characteristics of the FHR pattern, including the time of the day, position and activity of the mother, movement of the fetus [24-27]. In the current study, we chose the optimal timing, activity and position to maximize oxygenation of the fetus: postprandial, in the morning, at rest, and semi-sitting position.
Maternal COVID-19 infection can cause changes that can be observed in CTG due to reasons such as maternal hypoxia, cytokine storm, maternal pyrexia, uterine irritability, and placental intervillous thrombosis secondary to maternal hypercoagulable state, which may result with diminished transfer of oxygen through the placenta [10-15, 28].

Maternal inflammatory state and pyrexia is likely responsible from main CTG changes in COVID-19 infected mothers such as increased baseline FHR $>10 \%$ and fetal tachycardia (FHR $>180 \mathrm{bpm}$ ) (Figure 5). Inline with the results of the only study performed with 12 patients [29], in our study, all fetuses showed an increased baseline FHR compared to the initial recording. Traces with fetal tachycardia were mostly mild cases, but two severe COVID-19 cases had FHR $>200$ bpm which was most likely secondary to the maternal cytokine storm due to excessive inflammatory mediators and fetal sympathetic response. 
Table 4: Relationship between COVID severity and CTG features.

\begin{tabular}{|c|c|c|c|c|c|}
\hline \multirow[t]{2}{*}{ COVID-19 severity } & \multicolumn{2}{|c|}{ Mild } & \multicolumn{2}{|c|}{$\begin{array}{c}\text { Moderate/ } \\
\text { severe }\end{array}$} & \multirow[t]{2}{*}{ p-Value } \\
\hline & $\mathbf{n}$ & $\%$ & $\mathbf{n}$ & $\%$ & \\
\hline CTG category & & & & & $p=0.247$ \\
\hline Category 1 & 123 & 71.7 & 27 & 77.1 & \\
\hline Category 2 & 43 & 24.9 & 5 & 14.3 & \\
\hline Category 3 & 7 & 4.0 & 3 & 8.6 & \\
\hline CTG category changes & & & & & $p=0.460$ \\
\hline No & 138 & 80.2 & 29 & 82.8 & \\
\hline Category 1-2 & 10 & 5.8 & 2 & 5.7 & \\
\hline Category 2-3 & 3 & 1.7 & - & - & \\
\hline Category 1-3 & 7 & 4.1 & 1 & 2.9 & \\
\hline Category 2- 1 & 12 & 7.0 & 1 & 2.9 & \\
\hline Category 3-1 & 2 & 1.2 & 2 & 5.7 & \\
\hline Variability & & & & & $\mathrm{p}=0.315$ \\
\hline Absence of variability & 8 & 4.6 & - & - & \\
\hline Minimal variability & 38 & 22.0 & 9 & 25.7 & \\
\hline Normal variability & 119 & 68.8 & 26 & 74.3 & \\
\hline Marked variability ${ }^{\mathrm{b}}$ & 8 & 4.6 & - & - & \\
\hline Tachycardia/bradycardia & & & & & $p=0.744$ \\
\hline No & 161 & 93.1 & 32 & 91.4 & \\
\hline Tachycardia & 10 & 5.8 & 2 & 5.7 & \\
\hline Bradycardia & 2 & 1.1 & 1 & 2.9 & \\
\hline Acceleration & & & & & $p=0.792$ \\
\hline No & 25 & 14.5 & 4 & 11.4 & \\
\hline Yes & 148 & 85.5 & 31 & 88.6 & \\
\hline Deceleration & & & & & $p=0.870$ \\
\hline No & 130 & 75.1 & 25 & 71.4 & \\
\hline Early & 3 & 1.7 & 1 & 2.9 & \\
\hline Variable & 23 & 13.3 & 5 & 14.3 & \\
\hline Late & 14 & 8.2 & 4 & 11.4 & \\
\hline Prolonged & 3 & 1.7 & - & - & \\
\hline Uterine contractility & & & & & $p=0.960$ \\
\hline No & 49 & 28.4 & 10 & 28.6 & \\
\hline Yes & 114 & 65.9 & 23 & 65.6 & \\
\hline Tachysystole & 7 & 4.0 & 1 & 2.9 & \\
\hline Saw-tooth ${ }^{c}$ & 3 & 1.7 & 1 & 2.9 & \\
\hline
\end{tabular}

${ }^{\mathrm{a}}$ Fisher-Exact/chi-square test. ${ }^{\mathrm{b}}$ Increased variability which amplitude range is $>25$ beats/min for 1 min or longer was defined as ZigZag pattern in the literature [23]. ${ }^{\text {CS}}$ Shark-teeth-like increased uterine contractions.
Table 6: Logistic regression model based on COVID-19 categories.

\begin{tabular}{lrrrr}
\hline Variable & p-Value & OR $^{\mathrm{a}}$ & \multicolumn{2}{c}{$\begin{array}{c}\text { 95\% Confidence } \\
\text { interval (OR) }\end{array}$} \\
\cline { 4 - 5 } & & & Low & High \\
\hline Gestational week & 0.059 & 0.898 & 0.803 & 1.004 \\
CTG category $^{\mathrm{a}}$ & 0.125 & & & \\
Category 2 $_{\text {Category 3 }}$ & 0.107 & 0.375 & 0.114 & 1.235 \\
Baseline FHR (first) & 0.253 & 2.363 & 0.541 & 10.320 \\
Baseline FHR (last) & $0.034^{\mathrm{b}}$ & 0.955 & 0.915 & 0.996 \\
\hline
\end{tabular}

${ }^{a}$ Odds ratio. ${ }^{b}$ Statistically significant $(<0.05)$.

Maternal hypercoagulable state, maternal hypoxia and ARDS result with placental intervillous thrombosis and reduction in placental circulation which can cause acute fetal bradycardia in CTG trace [30, 31]. After acute fetal bradycardia was seen in a mother with severe COVID-19, the fetus was delivered with an emergency C/S operation in which the newborn had 1st min APGAR 7. The oxygen saturation was 88 without the nasal oxygen support and she went under invasive ventilation after delivery. However, at the time of CTG recording, the patient received continuous nasal oxygen support and the oxygen saturation was above 92.

Although most of the patients had normal variability, there were also cases with minimal (48 patients) and increased (nine patients) variability in our study because the population size was high enough. Maternal hypoxia and cytokine storm associated inflammatory cytokines cross the placenta and the fetal blood-brain barrier, and cause depression of fetal central nervous system [29]. This is observed as minimal variability $(<5 \mathrm{bpm})$ in CTG (Figure 1). Majority of our population had normal variability (159 patients). Inflammatory cytokines and maternal pyrexia can cause fetal autonomic instability. This is observed as increased variability $(>25 \mathrm{bpm}$ ) which results with ZigZag pattern in CTG trace. In our study, on the

Table 5: Relationship between COVID-19 severity and clinical features.

\begin{tabular}{|c|c|c|c|c|c|}
\hline \multirow[t]{2}{*}{ COVIDs Severity } & \multicolumn{2}{|c|}{ Mild } & \multicolumn{2}{|c|}{ Moderate/severe } & \multirow[t]{2}{*}{ p-Value ${ }^{c}$} \\
\hline & Mean $\pm \mathbf{S D}^{\mathrm{a}}$ & Median [IQR $]$ & Mean $\pm \mathbf{S D}^{\mathrm{a}}$ & Median [IQR $\left.{ }^{b}\right]$ & \\
\hline Gestational week & $36.40 \pm 3.44$ & $38.0[4.8]$ & $35.60 \pm 3.30$ & $37.0[5.0]$ & $p=0.079$ \\
\hline Baseline FHR (first) & $136.19 \pm 11.91$ & $140.0[10.0]$ & $134.57 \pm 12.62$ & $135.0[15.0]$ & $p=0.523$ \\
\hline Baseline FHR (last) & $138.37 \pm 11.61$ & $140.0[15.0]$ & $141.14 \pm 11.76$ & $140.0[20.0]$ & $p=0.158$ \\
\hline Apgar 1st min & $7.55 \pm 0.81$ & $8.0[1.0]$ & $7.17 \pm 1.55$ & $8.0[1.0]$ & $p=0.374$ \\
\hline Apgar 5th min & $9.09 \pm 0.77$ & $9.0[1.0]$ & $8.75 \pm 1.03$ & $9.0[0.0]$ & $p=0.106$ \\
\hline Birth weight, $\mathrm{g}$ & $3,101.03 \pm 599.10$ & $3,200.0[585.0]$ & $2,928.80 \pm 608.59$ & $3,020.0[650.0]$ & $p=0.135$ \\
\hline Min $\mathrm{O}_{2}$ saturation & $96.78 \pm 1.17$ & $97.0[2.0]$ & $93.43 \pm 2.75$ & $94.0[4.3]$ & $p=0.000^{d}$ \\
\hline
\end{tabular}

${ }^{\mathrm{a}}$ Standard deviation. ${ }^{\mathrm{b}}$ Interquartile range. ${ }^{\mathrm{c}}$ Mann-Whitney $\mathrm{U}$ test. ${ }^{\mathrm{d}}$ Statistically significant $(<0.05)$. 
contrary to Gracia-Perez-Bonfils A et al. [29], ZigZag pattern (Figure 2) was only seen in patients who were in mild category. No increased variability was observed in moderate and severe categories.

Maternal hypoxia and inflammatory cytokines can cause depression of fetal central nervous system which results with reduction of fetal movements and seen in CTG as loss of accelerations [30, 31]. In our study, not associated with COVID-19 severity, 30 patients showed loss of accelerations (Figure 3). Despite the majority of the patients had no decelerations, all types of decelerations especially variable decelerations were seen in CTG trace (Figures 3 and 4), and again exhibiting no association with the COVID-19 category. Although our study design prevents us from speculating about the cause of these decelerations, these results support our theory. Maternal hypoxia or hypotension and maternal hypercoagulable state leading to placental thrombosis and infarction which cause increased placental metabolism and uteroplacental insufficiency may be the reason of decelerations seen in CTG trace $[7,14,15]$.

Rarely, sinusoidal pattern can be observed in CTG trace as a result of chronic fetal anemia and acidosis due to both maternal and fetal destruction of red cells. Fetal autonomic instability caused by acute feto-maternal hemorrhage and fetal hypovolemia can also cause the pattern. Similar to the previous study [29], sinusoidal pattern was not seen in CTG traces.

Myometrial irritability due to maternal inflammatory state and maternal pyrexia is associated with increased uterine activity [16]. As expected, in our study increased uterine activity was observed in majority of the patients.

The main strength of our study is the high number of patients analyzed in the study population. While the only previous study analyzing the CTG features of COVID-19 pregnancies recruited 12 patients, we worked with 224 patients. Another major strength is that this is the first characterization of detailed CTG findings in women with acute COVID-19 infection.

The main limitations of our study are that study design does not allow determination of causality, and the number of moderate and severe COVID-19 cases is low. However, although the numbers were small in moderate and severe cases comparatively, since the population size is high, the small numbers are considered sufficient to present early results about COVID-19 during pregnancy. Other limitations are the lack of correlation between the CTG trace features and the newborn umbilical cord $\mathrm{pH}$, and the lack of knowledge about the possible effect of the cocktail of medications on the CTG.
Acknowledgments: The authors give special thanks to all healthcare personnel of the hospital who work devotedly for public health during COVID-19 pandemic.

Research funding: None declared.

Author contributions: SS: concept design, methodology, data collection, data analysis/interpretation and writing; DFO: reviewing and editing; EOT, FHO and SAS: data collection, data analysis/interpretation; HLK: data analysis/interpretation, OMT: supervision; DS: concept design, methodology, reviewing and editing.

Competing interests: The authors declare no conflicts of interest.

Informed consent: Verbal and written informed consent was obtained from all participants of the study. No funding was received for this study.

Ethical approval: This study was approved by the Ethics Committee of the Ankara City Hospital on September 16, 2020 with the number E1-20-1084.

\section{References}

1. World Health Organization (WHO). Coronavirus disease (COVID-19) overview webpage [Online]. Available from: https://covid19.who. int/ [Accessed 31 Jul 2021].

2. Schwartz DA, Graham AL. Potential maternal and infant outcomes from coronavirus 2019-nCoV (SARS-CoV-2) infecting pregnant women: lessons from SARS, MERS, and other human coronavirus infections. Viruses 2020;12:194.

3. Sahin D, Tanacan A, Erol SA, Anuk AT, Yetiskin FDY, Keskin HL, et al. Updated experience of a tertiary pandemic center on 533 pregnant women with COVID-19 infection: a prospective cohort study from Turkey. Int J Gynaecol Obstet 2021;152:328-34.

4. Bellos I, Pandita A, Panza R. Maternal and perinatal outcomes in pregnant women infected by SARS-CoV-2: a meta-analysis. Eur J Obstet Gynecol Reprod Biol 2021;256:194-204.

5. Dashraath P, Wong JLJ, Lim MXK, Lim LM, Li S, Biswas A, et al. Coronavirus disease 2019 (COVID-19) pandemic and pregnancy. Am J Obstet Gynecol 2020;222:521-31.

6. Zaigham M, Andersson 0 . Maternal and perinatal outcomes with COVID-19: a systematic review of 108 pregnancies. Acta Obstet Gynecol Scand 2020;99:823-9.

7. Bakay K, Varolan A, Yazgan A, Akyol A, Davas İ. Comparison of modified biophysical profile with Doppler ultrasonographic analysis in determining fetal well being in the third trimester. Gynecol Obstet Reproductive Med 2013;19:67-75.

8. Pinas A, Chandraharan E. Continuous cardiotocography during labour: analysis, classification and management. Best Pract Res Clin Obstet Gynaecol 2016;30:33-47.

9. Chandraharan E, Arulkumaran S. Prevention of birth asphyxia: responding appropriately to cardiotocograph (CTG) traces. Best Pract Res Clin Obstet Gynaecol 2007;21:609-24.

10. Chen G, Wu D, Guo W, Cao Y, Huang D, Wang H, et al. Clinical and immunological features of severe and moderate coronavirus disease 2019. J Clin Invest 2020;130:2620-9. 
11. Chousterman BG, Swirski FK, Weber GF. Cytokine storm and sepsis disease pathogenesis. Semin Immunopathol 2017;39: 517-28.

12. Ye Q, Wang B, Mao J. The pathogenesis and treatment of the 'Cytokine Storm' in COVID-19. J Infect 2020;80:607-13.

13. Mehta P, McAuley DF, Brown M, Sanchez E, Tattersall RS, Manson JJ. COVID-19: consider cytokine storm syndromes and immunosuppression. Lancet 2020;395:1033-4.

14. Rasmussen SA, Smulian JC, Lednicky JA, Wen TS, Jamieson DJ. Coronavirus Disease 2019 (COVID-19) and pregnancy: what obstetricians need to know. Am J Obstet Gynecol 2020;222:415-26.

15. Chen H, Guo J, Wang C, Luo F, Yu X, Zhang W, et al. Clinical characteristics and intrauterine vertical transmission potential of COVID-19 infection in nine pregnant women: a retrospective review of medical records. Lancet 2020;395:809-15.

16. Vivanti AJ, Vauloup-Fellous C, Prevot S, Zupan V, Suffee C, do Cao J, et al. Transplacental transmission of SARS-CoV-2 infection. Nat Commun 2020;11:3572.

17. Ayres-de-Campos D, Spong CY, Chandraharan E. FIGO consensus guidelines on intrapartum fetal monitoring: Cardiotocography. Int J Gynaecol Obstet 2015;131:13-24.

18. Modanlou HD, Murata Y. Sinusoidal heart rate pattern: reappraisal of its definition and clinical significance. J Obstet Gynaecol Res 2004;30:169-80.

19. Cantini F, Goletti D, Petrone L, Najafi Fard S, Niccoli L, Foti R. Immune therapy, or antiviral therapy, or both for COVID-19: a systematic review. Drugs 2020;80:1929-46.

20. National Health Commission of the People's Republic of China. Chinese management guideline for COVID-19 (version 6.0); 2020. Available from: http://en.nhc.gov.cn/2020-03/29/c_ 78469.htm.

21. Ayres-de-Campos D, Nogueira-Reis Z. Technical characteristics of current cardiotocographic monitors. Best Pract Res Clin Obstet Gynaecol 2016;30:22-32.

22. Macones GA, Hankins GDV, Spong CY, Hauth J, Moore T. The 2008 National Institute Of Child Health and Human Development
Workshop report on electronic fetal monitoring: update on definitions, interpretation, and research guidelines. J Obstet Gynecol Neonatal Nurs 2008;37:510-5.

23. Gracia-Perez-Bonfils A, Vigneswaran K, Cuadras D, Chandraharan E. Does the saltatory pattern on cardiotocograph (CTG) trace really exist? The ZigZag pattern as an alternative definition and its correlation with perinatal outcomes. J Matern Fetal Neonatal Med 2019;1-9. https://doi.org/10.1080/ 14767058.2019.1686475.

24. Maeda K. Invention of ultrasonic Doppler fetal actocardiograph and continuous recording of fetal movements. J Obstet Gynaecol Res 2016;42:5-10.

25. Bradford B, Maude R. Fetal response to maternal hunger and satiation - novel finding from a qualitative descriptive study of maternal perception of fetal movements. BMC Pregnancy Childbirth 2014;14:288.

26. Ehrström C. Circadian rhythm of fetal movements. Acta Obstet Gynecol Scand 1984;63:539-41.

27. Stone PR, Burgess W, McIntyre JPR, Gunn AJ, Lear CA, Bennet L, et al. Effect of maternal position on fetal behavioural state and heart rate variability in healthy late gestation pregnancy. J Physiol 2017;595:1213-21.

28. Wang D, Hu B, Hu C, Zhu F, Liu X, Zhang J, et al. Clinical characteristics of 138 hospitalized patients with 2019 novel coronavirus-infected pneumonia in Wuhan, China. J Am Med Assoc 2020;323:1061-9.

29. Gracia-Perez-Bonfils A, Martinez-Perez O, Llurba E, Chandraharan E. Fetal heart rate changes on the cardiotocograph trace secondary to maternal COVID-19 infection. Eur J Obstet Gynecol Reprod Biol 2020;252:286-93.

30. Martinelli I, Ferrazzi E, Ciavarella A, Erra R, Iurlaro E, Ossola M, et al. Pulmonary embolism in a young pregnant woman with COVID-19. Thromb Res 2020;191:36-7.

31. Terpos E, Ntanasis-Stathopoulos I, Elalamy I, Kastritis E, Sergentanis TN, Politou M, et al. Hematological findings and complications of COVID-19. Am J Hematol 2020;95:834-47. 